\title{
Histologic Type of Cancer
}

National Cancer Institute

\section{Source}

National Cancer Institute. Histologic Type of Cancer. NCI Thesaurus. Code C154802.

The determination of the histologic type of cancer in a sample. 